\title{
O SIGNIFICADO DO TQM E MODELOS DE IMPLEMENTAÇÃO
}

\section{GESTÃO}

\&

PRODUÇÃO

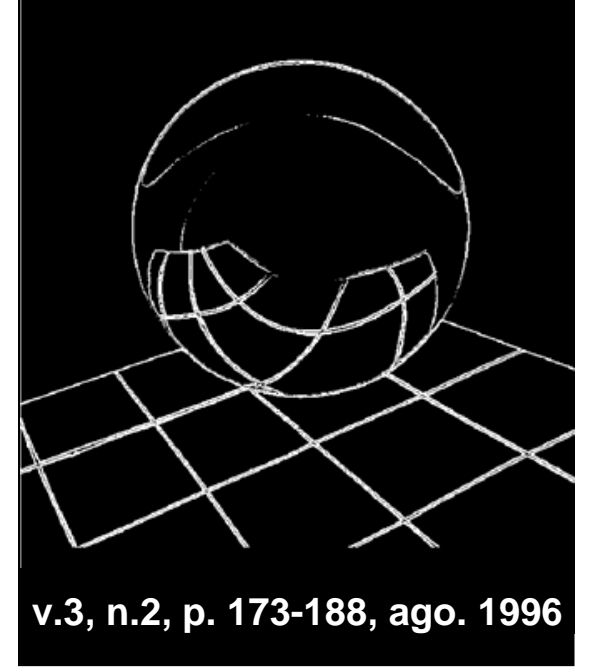

Aguinaldo Aragon Fernandes

Doutorando do Departamento de Engenharia de Produção da Escola Politécnica de Engenharia da USP

Pedro Luiz de Oliveira Costa Neto

Professor Doutor do

Departamento de Engenharia de Produção Escola Politécnica da Universidade de São Paulo

\section{Resumo}

A partir dos 14 pontos do Dr. Deming, o artigo procura explorar o significado do TQM conforme os seus elementos fundamentais, ou seja, "foco no cliente", "foco no processo", "comprometimento de todos", "orientação para resultados", "aprendizagem” e "liderança”, mostrando como se relacionam, bem como discutindo o papel de abordagens gerenciais para a sua implementação. São focalizados também os modelos teóricos preconizados para a implementação do TQM, juntamente com abordagens práticas empregadas por várias organizações, em comparação com aqueles modelos. A partir da análise destes modelos discutem-se os fatores críticos da implementação do TQM nas organizações e sugere-se um conjunto de atitudes a serem tomadas pelas empresas brasileiras.

\section{Palavras-chave: qualidade, qualidade total, gestão para a qualidade, modelos de implementação, competição global.}

\section{TQM - Fundamentos}

$\mathrm{P}$ odemos atribuir ao Dr. W. E. Deming a revolução gerencial ocorrida dos anos 70 até os dias atuais. Os ensinamentos por ele difundidos no Japão, na década de 50, e aplicados e evoluídos naquele país, alteraram radicalmente as bases da competição global.
Apesar de não haver um consenso sobre o significado dos famosos 14 pontos de DEMING (1986), tentativas têm sido realizadas no sentido de determinar a amplitude de cada um dos pontos e como eles formam os princípios da Gestão para a Qualidade Total. 
Em recente estudo psicométrico sobre os 14 pontos de Deming, TAMINI et al (1995), desenvolveram um instrumento para mensurar esses princípios. GITLOW \& GITLOW (1987) apresentam uma interpretação de cada um deles.

Pela análise mais detalhada desses 14 pontos, pode-se perceber claramente que os princípios baseiam-se na responsabilidade e no comprometimento da administração, no entendimento das necessidades dos clientes, no entendimento dos processos da organização e no envolvimento de todos, a partir de novas filosofias de gestão de recursos humanos.

Apesar de Deming não ter explicitado a relação de causa-e-efeito entre os seus princípios, hoje, passados mais de 30 anos, a prática das empresas, principalmente no Japão e nos países asiáticos, nos Estados Unidos e na Europa, nos permite compreender essa relação.

O desenvolvimento conseqüente de um corpo teórico sobre a qualidade, representado pelos trabalhos de JURAN (1990), FEIGENBAUM (1986), ISHIKAWA (1993), CROSBY (1984), SHIBA (1993), GALGANO (1993), GARVIN (1992), MERLI (1993), IMAI (1988), TAGUCHI (1978), OSADA (1992), CONTI (1995) e outros, bem como os relatos de casos de êxito e fracasso com a aplicação da filosofia em MAIN (1995), GREEN (1995) e o advento dos Prêmios da Qualidade, MBNQA (1987), FPNQ (1992) e European Quality Award in ZAIRI (1994), que tiveram o Prêmio Deming (1951) como precursores, propiciam o entendimento do TQM como uma nova filosofia de gestão baseada em um conjunto de princípios, sistemas e ferramentas.

Os primeiros a sistematizar os ensinamentos de Deming em uma filosofia de gestão foram os japoneses. Essa filosofia é considerada como uma estratégia de negócio, cuja essência é o projeto, a produção e a oferta de novos produtos e serviços a fim de atingir a satisfação total do cliente a um preço aceitável.
O modelo japonês de qualidade total, muito bem sintetizado por GALGANO (1993), abrange uma combinação de princípios, mecanismos gerenciais e técnicas operacionais. Esta filosofia é composta por Premissas Básicas, Cultura da Qualidade, Processos Fundamentais e Liderança do Máximo Executivo.

As premissas constituem-se em: valores da empresa relativos aos clientes, aos colaboradores internos e aos fornecedores; $\boldsymbol{a}$ qualidade estar em primeiro em qualquer situação; novo significado da qualidade em termos de qualidade negativa e positiva; o entendimento da melhoria contínua, tanto no que diz respeito às pequenas melhorias como às inovações; a participação de todos os colaboradores da empresa e o conceito de "breakthrough", ou seja, inovações drásticas nos processos e sistemas gerenciais.

A cultura da qualidade constitui-se em: mecanismos mentais, representados pelo entendimento das relações de causa-e-efeito, aplicação de métodos de resolução de problemas e de planejamento de melhorias; lógicas de gestão, tais como atenção centrada nos processos, reconhecimento dos esforços do pessoal, qualidade em toda a cadeia de relacionamento produtivo, incluindo os fornecedores, e gestão visual; mentalidade difusa, que são atitudes no dia a dia do pessoal em termos de respeito aos colaboradores, gestão a partir de fatos e dados, concentração nos pontos vitais, o próximo processo e o seu cliente e controle do processo.

Os processos fundamentais são considerados os aspectos visíveis do TQM e compõem-se de: direção por políticas, que preconiza o desdobramento dos objetivos estratégicos, por toda a organização, visando a articulação e o sincronismo de todas as ações da empresa para um determinado período de tempo; a melhoria do trabalho diário que objetiva a manutenção dos processos da empresa dentro de certos padrões de controle; o diagnóstico do presidente que objetiva a verificação do sistema da qualidade pelo próprio dirigente 
máximo da empresa; a formação intensiva dos colaboradores internos e externos; círculos de controle da qualidade e a gestão do produto ou serviço, que compreende os processos relativos ao desenvolvimento de produtos, produção e relacionamento com a cadeia de fornecimento.

$\mathrm{O}$ componente liderança do máximo executivo, no modelo japonês, é o principal promotor da introdução, manutenção e evolução da qualidade total na empresa; é quem deve definir as políticas e os objetivos de melhoria, bem como fornecer os meios para atingir os objetivos estipulados.

Como a história recente nos demonstrou, os princípios de Deming, sistematizados conforme uma filosofia e um modelo de gestão, provaram seus méritos, tornando as empresas japonesas extremamente competitivas, desencadeando reação significativa de empresas ocidentais, mais notadamente empresas que já competiam no mercado global.
A formulação de modelos de Gestão da Qualidade Total tais como os Prêmios Nacionais da Qualidade como o MBQNA (1995) e o EQA, in ZAIRI (1994), modelos teóricos como os apresentados por SHIBA (1993) e MERLI (1993), este último denominado modelo Europeu, e estudos para determinar os fatores críticos de sucesso do TQM, PORTER \& PARKER (1993), MENDOLOWITZ (1991) e SARAPH et al (1989), além de serem respostas ocidentais à excelência japonesa, contribuíram também para sistematizar os princípios básicos de Deming, porém introduzindo a componente resultados do negócio.

De acordo com os critérios de avaliação mais recentes do MBQNA (1995), o TQM pode ser visualizado pela relação entre sete elementos, conforme mostra a figura 1.

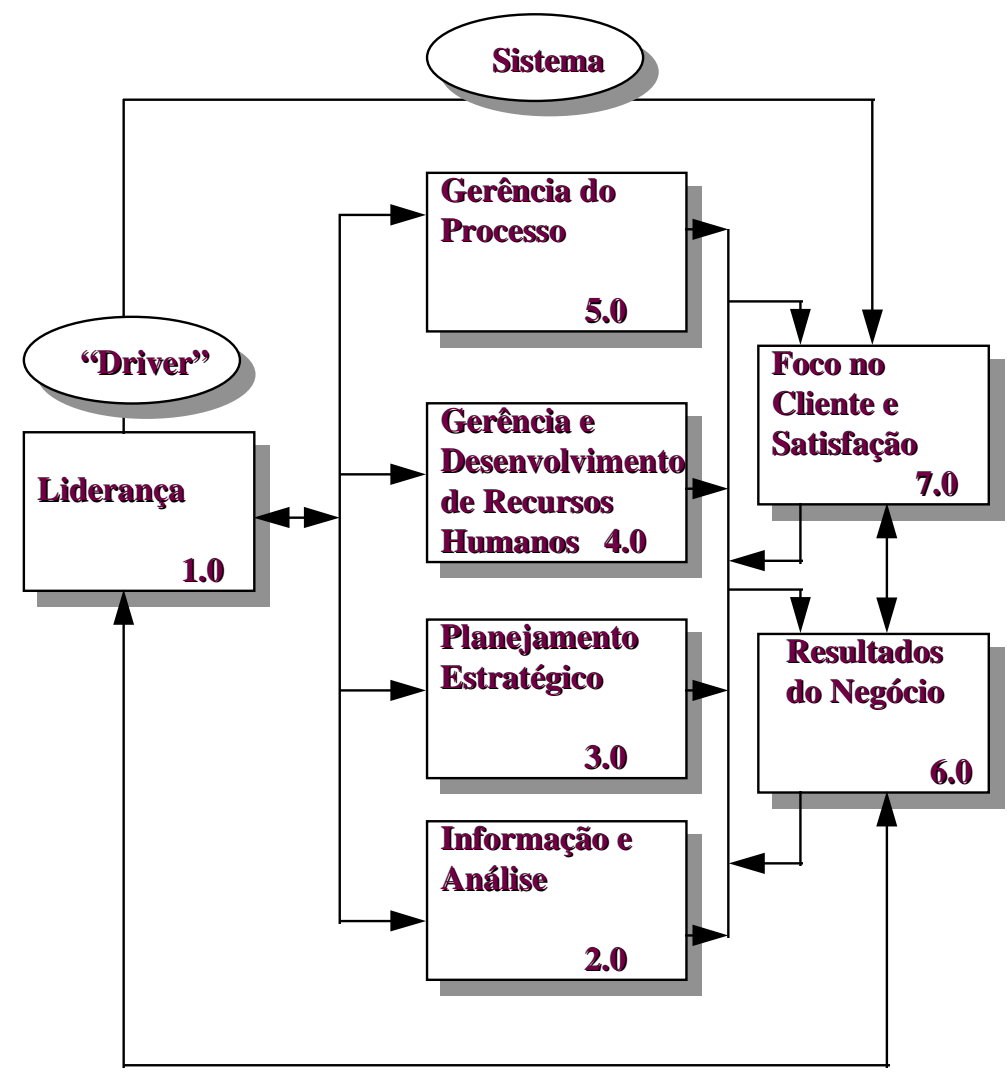

\section{Meta}

- Satisfação do cliente

- Satisfação em relação à concorrência

- Retenção do cliente

- Ganho de "market share"

\section{Medidas de Progresso}

- Qualidade do produto e serviço

- Melhoria da produtividade

- Redução/eliminação de perdas

- Desempenho dos fornecedores

- Resultados financeiros

Figura 1: Baldrige Award Criteria Framework Dynamic Relationship - MBQNA (1995) 
Como se pode inferir desse esquema, a Liderança da alta administração é o promotor (indispensável) do TQM. Este elemento está associado a todos os pontos da filosofia de Deming, pois, sem a liderança necessária, a mudança cultural representada pelo TQM é impossível de ser atingida.

O elemento "Informação e Análise" é congruente com um dos princípios que é a gestão com base em fatos e dados.

O elemento “Planejamento Estratégico” é congruente com o princípio de desenvolvimento de metas e a filosofia da organização, cuja responsabilidade é da alta administração.

O elemento "Desenvolvimento e Gerência de Recursos Humanos” alinha-se com os princípios de instituição de métodos modernos de capacitação, supervisão da melhoria contínua, erradicação do temor, fomento do orgulho pelo trabalho, educação e recapacitação para todos.

O elemento "Gerência do Processo" alinha-se com os princípios de compreensão da melhoria contínua, eliminação da inspeção em massa, melhoramento do sistema, eliminação das barreirras organizacionais e substituição da administração por cifras.

Por fim, os elementos "foco no cliente e satisfação" e "resultados do negócio”, são congruentes com o modelo de Reação em Cadeia também preconizado por Deming.

Outros enfoques, similares ao proposto pelo MBNQA, são os de MENDELOWITZ (1991) e o EQA in ZAIRI (1994), conforme apresentados nas Figuras 2 e 3, respectivamente.

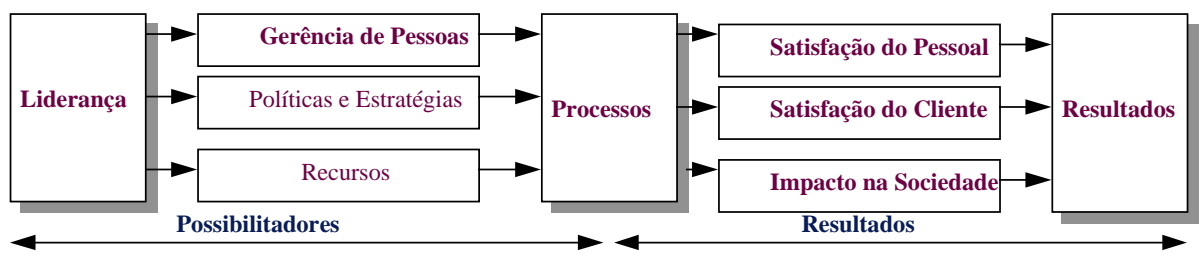

Figura 2: Modelo do European Quality Award

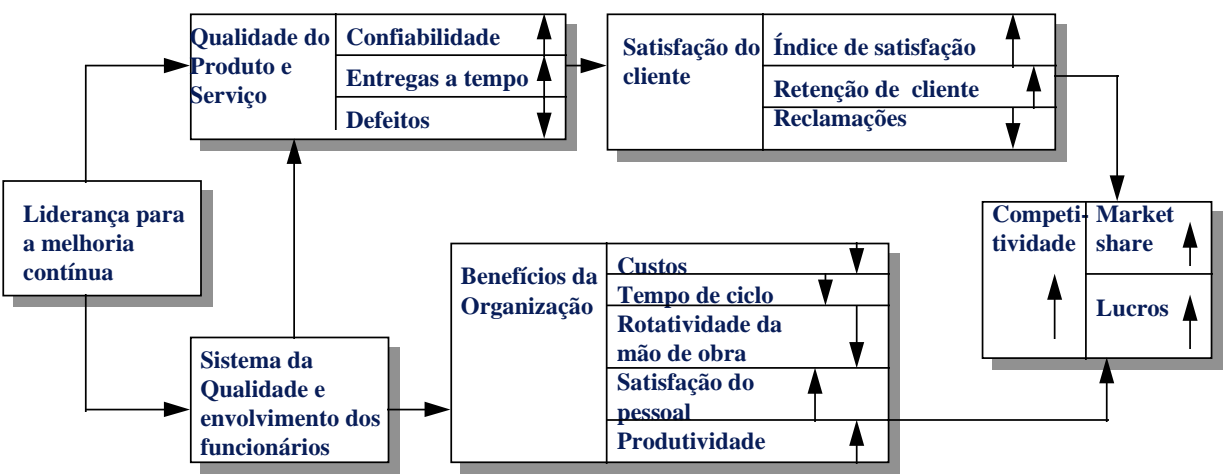

Figura 3: Modelo de Sistema da Qualidade - General Accounting Office

Combinando os modelos de TQM acima descritos com as definições dadas por SHIBA (1993), DOBBINS (1995), LES LANDES (1995), EARLY \& GODFREY (1995), HOOVER JR. (1995) e outros, pode-se conceituar TQM como: ...uma filosofia de negócio sistematizada, orientada para resultados, cuja obtenção baseia-se na busca permanente da satisfacão do cliente, com desempenho superior ao da concorrência, no foco nos processos decorrente do constante alinhamento destes às necessidades mutáveis e evolutivas dos 
clientes e com o envolvimento de todos os colaboradores do empreendimento, tanto internos como externos, sendo que a promoção, evolução e melhoria desta filosofia é responsabilidade indelegável do dirigente máximo da orqanização.
Para se proseguir com esta análise do significado de TQM, procura-se desdobrar o conceito acima, discutindo o significado dos principais elementos desta filosofia de gestão.

\section{Desdobrando o Conceito de TQM}

\subsection{Satisfação Total do Cliente}

$\mathrm{A}$

rigor, uma empresa somente consegue sobreviver se atende às necessidades dos clientes. De acordo com SHIBA (1993), prover a satisfação do cliente implica atender às suas necessidades, prevê-las e excedê-las.

Para sobreviver, qualquer negócio precisa atender aos padrões mínimos de qualidade oferecidos pelo conjunto de indústrias e empresas de um ramo de negócio. É o que se denomina de qualidade compulsória. Para ser competitiva, uma empresa precisa exceder em qualidade aos olhos dos clientes e relativamente aos concorrentes. E para prosperar no longo-prazo e perenizar sua sobrevivência, a empresa precisa prever as necessidades.

Ao contrário de empresas caracterizadas como "product-out", conforme definição de MERLI (1994), empresas orientadas pela filosofia de qualidade total procuram entender os requisitos dos clientes ouvindoos permanentemente, seja mediante pesquisas de marketing, pesquisas focalizadas, grupos focais, visitando a organização do cliente em todos os pontos em que haja contato (em que ocorrem os "momentos da verdade”), tentando incorporar esses requisitos ao projeto de produtos e serviços.

Adicionalmente, procuram obter constante "feedback" acerca da qualidade de seus produtos e serviços (possibilidade de adequação ao uso), no sentido de promover alinhamento ou melhoria de processos críticos de seu negócio, principalmente sobre aqueles que contribuem para a qualidade conforme percebida pelo cliente.
Como a percepção dos clientes sobre a qualidade evolui com o tempo, sendo dinâmica, ouvi-los permanentemente torna-se condição sine qua non para a sobrevivência, pois o que excede hoje pode tornar-se atributo da qualidade compulsória amanhã.

Entretanto, somente isso não basta. É preciso também monitorar os competidores. De nada adianta atender às necessidades dos clientes se os principais competidores as estão excedendo e criando vantagens competitivas duradouras.

Já para prever as necessidades dos clientes, a empresa deve entender as futuras implicações da evolução do cenário tecnológico, político e econômico para a sociedade, visando vislumbrar novas configurações estruturais da indústria e do mercado, bem como novos negócios e mercados, e definir quais competências e habilidades básicas deverão ser desenvolvidas ou adquiridas, conforme definido por PRAHALAD \& HAMEL (1990), e que serão críticas para sobreviver em um futuro cenário de competição. Isto significa dizer que uma empresa pode atingir um patamar elevado de qualidade total e ser uma "world class company” no curto e médio-prazo, porém pode não sobreviver no futuro se não houver clientes aos quais possa vender seus produtos e serviços. A história tem demonstrado este fato com bastante freqüência (exemplo mais recente é a indústria de computadores de grande porte).

As implicações do significado da satisfação do cliente em uma empresa orientada para a qualidade total são: (1) os processos gerenciais e de negócios devem estar 
alinhados para satisfazer às necessidades dos clientes; (2) a melhoria contínua dos processos somente tem sentido se agregar valor para o cliente, em termos dos atributos críticos da qualidade, como percebidos por ele; (3) a melhoria contínua está vinculada à evolução da qualidade, como percebida pelo cliente; (4) a empresa deve, constantemente, comparar-se com referenciais de excelência;
(5) o planejamento estratégico e os objetivos de aperfeiçoamento devem se pautar-se pelas necessidades atuais e latentes dos clientes e pela comparação do desempenho relativamente aos competidores; (6) a satisfação do cliente deve ser constantemente medida; (7) os requisitos dos clientes devem ser incorporados ao projeto dos produtos e serviços.

\subsection{Orientação Para Resultados}

Atualmente, uma empresa que deseja ser competitiva, crescer e prosperar deve produzir bens e serviços que, além de satisfazer aos requisitos e necessidades dos clientes, sejam superiores em qualidade aos produtos e serviços dos competidores.

Isso significa que as etapas de adequação aos padrões, ao uso, ao custo e às necessidades latentes (ainda não percebidas pelos clientes e nem pelos concorrentes) como descritas por SHIBA (1993), devem estar incorporadas na estratégia e no trabalho do dia-a-dia de um empreendimento.

Devido aos grandes avanços observados nas estratégias de manufatura nos últimos anos, podemos verificar atualmente uma forte relação entre preço e qualidade como critério ganhador de pedidos.

Essa relação tem induzido as empresas a concentrar-se em objetivos quantitativos no que diz respeito a atributos de projeto e processo, visando redução de custo e conseqüente aumento dos lucros, acompanhado de aumento da qualidade e, em alguns casos, em processos voltados para a introdução de inovações no mercado.

A orientação para resultados estabelece os parâmetros quantitativos de melhoria dos processos.

Ao contrário dos modelos de TQM de $1^{\text {a }}$ geração, os modelos ocidentais de $2^{\text {a }}$ geração são orientados para resultados, contemplando não somente o médio e longo-prazo como também o curto-prazo. A abordagem de resultados foi uma resposta consciente de empresas globais ocidentais para recuperar, em pequeno espaço de tempo, o terreno perdido em relação às empresas japonesas. MERLI (1993) apresenta uma interessante análise comparativa entre os dois modelos.

Para tanto, essas empresas procuraram focalizar seus esforços nos processos críticos que efetivamente agregavam valor aos clientes, estabelecendo objetivos de redução de defeitos, redução do ciclo de tempo do projeto de produtos e da produção, assim como empregaram o "benchmarking”, ferramenta proposta por CAMP (1989), para reestruturar rapidamente os processos relevantes.

Outro aspecto importante é que, ao desdobrar estes objetivos por toda a organização, mediante abordagens tais como o "hoshin kanri” (técnica que procura desdobrar por toda a organização, tanto verticalmente como horizontalmente, objetivos anuais de melhoria), como preconizado por AKAO (1988), criaram parte das condições psicológicas e motivacionais que dão sentido ao trabalho e à contribuição dos colaboradores.

Isso significa que a melhoria contínua não é uma abordagem desvinculada dos objetivos temporais da organização.

Isto também se refletiu na forma de recompensa dos esforços dos colaboradores.

Dependendo do tipo de organização, do negócio em que está inserida, do nível de competição etc., muitos objetivos podem ser estabelecidos, os quais implicarão a melhoria dos processos. Por exemplo, como proposto por GOLD (1985), objetivos de:

redução do time to market. 
redução do cycle time.

redução do número de defeitos dos processos.

aumento do índice de satisfação dos clientes.

aumento da taxa de entregas a tempo.

aumento do índice de satisfação dos colaboradores.

redução do tempo de preparação de máquinas.

aumento do índice de disponibilidade de equipamentos.

redução dos custos de produção.

redução dos custos de materiais comprados. redução dos custos de não-conformidade. aumento da produtividade do custo total.

As implicações da orientação para resultados são: (1) objetivos de melhoria podem ser planejados; (2) objetivos de melhoria devem ser desdobrados por toda a organização; (3) sistema de medição de desempenho deve ser introduzido, visando medir até que ponto os objetivos são atingidos; (4) objetivos de melhoria podem ser estabelecidos em base anual e plurianual e (5) objetivos de melhoria devem estar vinculados aos objetivos estratégicos da organização.

\subsection{Foco nos Processos}

Como vimos anteriormente, a melhoria contínua está vinculada à evolução das necessidades dos clientes e ao desempenho superior dos competidores.

Está implícita no conceito de foco nos processos a idéia de que qualquer atividade pode ser aperfeiçoada se, sistematicamente, o aperfeiçamento é planejado, se a prática corrente é entendida, se as soluções são planejadas e implementadas, os resultados e suas causas são analisados e se são desencadeadas, ações corretivas no sentido de estabilizar ou melhorar o processo (SHIBA, 1993).

De acordo com este autor, a melhoria contínua pode ser vista sob três aspectos.

O primeiro é o controle do processo. Tem por objetivo a manutenção do processo dentro de um padrão pré-determinado de desempenho. O processo deve ser monitorado e, caso esteja fora de controle, ações corretivas devem ser desencadeadas para que o padrão de desempenho retorne ao estado original ou esperado. Geralmente, o controle do processo é considerado como componente do "daily-routine-work".

O segundo é a melhoria reativa. Tem por objetivo a melhoria dos processos que apresentam, sistematicamente, grande variabilidade. A ação de melhoria é realizada no sentido de eliminar as causas da variabilidade.
O terceiro é a melhoria proativa. Tem por objetivo melhorias inovadoras e drásticas nos processos, visando satisfazer os clientes e eliminar, reduzir ou ultrapassar vantagens competitivas da concorrência. Está associado ao conceito de "breakthrough”.

É importante compreender que todas as três abordagens são desenvolvidas considerando fatos e dados.

O foco no processo também significa que a gestão deve preocupar-se com processos e não com funções estanques, pois estas individualmente não produzem os resultados de melhoria. Os processos, ao contrário, são os geradores de resultados.

Portanto, foco no processo implica o trabalho de equipes multifuncionais ao longo de um processo, fazendo com que barreiras departamentais sejam extintas. Por exemplo, abordagens modernas de desenvolvimento de produto, tais como a Engenharia Simultânea, exigem a formação de equipes multidisciplinares compostas por elementos do marketing, do cliente, dos fornecedores, da engenharia do produto, engenharia de processo, logística e engenharia de fabricação.

O foco no processo também implica o entendimento do que Deming denominou de processo ampliado, ou seja, reconhecendo a 
importância do relacionamento da empresa com seus fornecedores e canais de distribuição, pois os objetivos de melhoria dependem da qualidade destes.

O conceito de processo ampliado levou à elaboração de novas estratégias de produção, tais como a produção enxuta e "just-intime”, (WOMACK \& JONES, 1994).

O entendimento da importância dos processos em uma organização implica o reconhecimento de que o próximo processo também deve ser considerado como cliente.
As implicações para as organizações acerca do significado de foco nos processos são: (1) a redução da variabilidade dos processos está associada à redução de custos; (2) atenção deve ser dada aos processos relacionados com clientes, desenvolvimento de novos produtos, fornecedores e fabricação, considerados críticos para qualquer tipo de empreendimento; (3) a melhoria contínua dos processos deve estar relacionada com as necessidades dos clientes.

\subsection{Comprometimento de Todos}

Talvez este seja um dos elementos mais fundamentais da filosofia gerencial de TQM, pois são as pessoas que operam processos, os quais geram resultados objetivando a satisfação dos clientes.

Envolvimento de todos significa a participação de pessoas de todos os níveis da organização no aperfeiçoamento contínuo dos processos e no "daily-routine-work".

Recente pesquisa demonstrou que a satisfação dos empregados é um dos principais fatores na determinação da qualidade dos produtos e conseqüente satisfação dos clientes, (LARSON \& SINHA, 1995).

No contexto do TQM, o envolvimento de todos requer novas abordagens de organização do trabalho, de aprendizagem, de gestão de recursos humanos e de comunicação entre a administração e seus colaboradores.

As abordagens de organização do trabalho são baseadas em equipes e no que se denomina de "empowerment".

De acordo com KATZENBACH \& SMITH (1993), uma equipe é um pequeno número de pessoas com habilidades complementares que são comprometidas com um propósito comum, estabelecem metas de desempenho e abordagens pelas quais se sentem mutuamente responsáveis.
Equipes podem ser classificadas, segundo SHIBA (1993), em três tipos, conforme mostra a figura 4.

De acordo com este autor, círculos de controle da qualidade são equipes informais e orientadas para o controle dos processos (daily-routine-work) e à melhoria reativa; equipes de melhoria da qualidade são forças-tarefas temporárias orientadas para a melhoria reativa e equipes multi-funcionais são forças-tarefa também temporárias e orientadas para a melhoria proativa.

O empowerment visa a constituição de equipes autônomas às quais são atribuídas responsabilidades, orientadas para objetivos de desempenho de melhoria, desdobrados a partir dos objetivos anuais e plurianuais estabelecidos no contexto da estratégia da organização. Para a formação de equipes dessa natureza é necessária a capacitação de todos para que se tornem, conforme TRIBUS (1995), competentes automáticos, ou seja, indivíduos possuidores de conhecimentos e habilidades e que sabem exatamente como uma tarefa deve ser planejada, executada e melhorada, sem o auxílio de supervisão.

As abordagens de aprendizagem necessárias neste contexto, devem ser orientadas para o que GARVIN (1993) definiu como a organização aprendiz. 


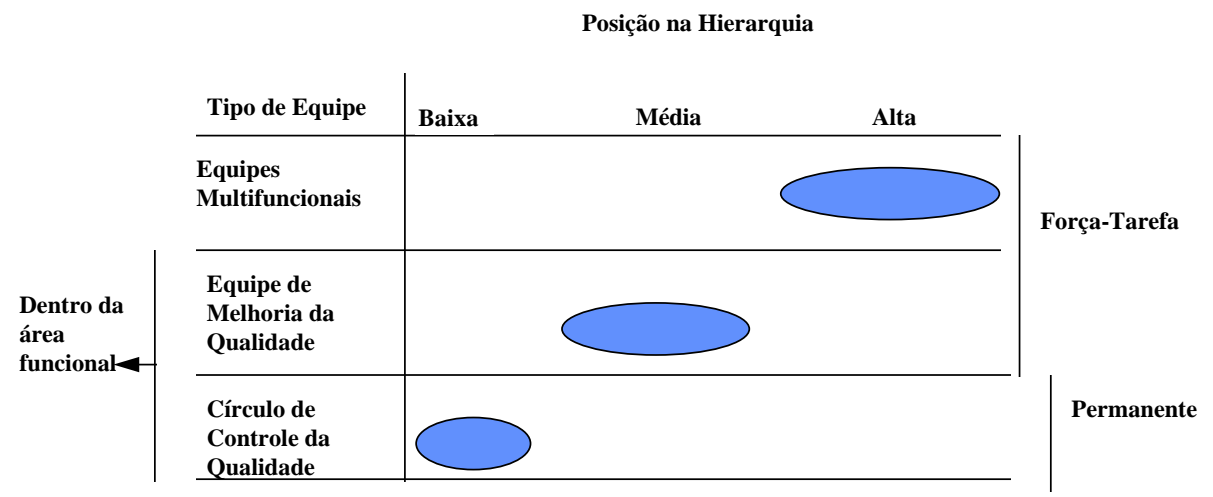

Figura 4: Tipos de Equipes

As organizações voltadas para a aprendizagem, de acordo com aquele autor, são habilitadas em cinco atividades principais: resolução sistemática de problemas, experimentação de novas abordagens, aprendizado com sua própria experiência e história passada, aprendizado com experiências e melhores práticas de outros e transferência de conhecimento rápida e eficaz a toda a organização.

Uma organização não orientada para a aprendizagem não tem a capacidade de melhorar continuamente os seus processos.

Conforme esta ótica, as pessoas devem ser capacitadas no uso de ferramentas da qualidade, na resolução de problemas, nos métodos de trabalho em equipe, planejamento de melhorias e medição de resultados. Para ser efetiva, a aprendizagem deve ser realizada em cascata, ou seja, gerente treina subordinado e assim sucessivamente. Com isso, as resistências dos gerentes de nível médio podem ser removidas.

A nova gestão de recursos humanos, num ambiente de TQM, torna obsoleta a tradicional descrição de cargos, pois as pessoas são habilitadas em muitas tarefas e funções, os erros são vistos como oportunidades de melhoria e os ganhos com atividades de aperfeiçoamento da qualidade são recompensados, monetariamente ou não, assim como são valorizados os aspectos relativos à qualidade de vida e à facilidade de obtenção de empregos por parte dos colaboradores internos, ou seja, a empresa empenha-se em fornecer as condições necessárias para que os colaboradores possam colocar-se facilmente no mercado. Essa facilidade decorre do conhecimento e da habilidade adquiridos pelo colaborador durante sua permanência na empresa.

A comunicação entre a administração e as equipes é um elo vital para que os objetivos de melhoria sejam atingidas. A alta administração deve comunicar os objetivos de melhoria, a visão e a missão da organização, reforçar a constância de propósito, fornecer feedback do desempenho das equipes e divulgar os casos de êxito, visando manter as equipes vivas e motivadas.

\subsection{Responsabilidade do Dirigente Máximo da Organização}

Sem a liderança do máximo executivo de uma organização, a introdução, a implementação e a evolução da filosofia de TQM estão fadadas ao fracasso.

A abordagem de TQM exige envolvimento e comprometimento do alto executivo no esforço de melhoria contínua.
Esse envolvimento e comprometimento é representado por atitudes e ações claras e visíveis em termos de estabelecimento da visão e missão da organização e dos objetivos de melhoria, comunicação da visão, da missão e dos objetivos a toda a organização, tornar a missão transparente e 
palpável, liderar pelo exemplo, realizar contatos periódicos com o "chão-defábrica”, fornecer os meios necessários para que os colaboradores desempenhem suas tarefas, ouvir as pessoas de todos os níveis, trabalhar em equipe, trabalhar educando seus executivos imediatos e a média gerência, manter a visão de longo-prazo e a constância de propósito, fomentar o orgulho pelo trabalho por parte dos colaboradores, aplaudir publicamente os resultados bem sucedidos de melhoria da qualidade e verificar pessoalmente a implementação, a manutenção e a evolução do TQM.

\subsection{Filosofia de Negócio Sistematizada}

TQM é uma filosofia abrangente e sistematizada de negócio. Ou seja, valores, políticas, sistemas de gestão, estratégias e uso de ferramentas compõem uma estrutura cujos elementos estão logicamente relacionados.

Por exemplo, ao empregar os modelos de $1^{\text {a }}$ geração de qualidade total, no início e no meado dos anos 80, algumas empresas norte-americanas pensavam que a chave do êxito japonês residia nos círculos de controle da qualidade ou no uso isolado de ferramentas da qualidade, como o controle estatístico do processo.

Como hoje sabemos, esses elementos são apenas partes de um grande quebra-cabeça.

Para melhor compreendermos o significado de "filosofia sistematizada de gestão" é importante discutirmos os modelos de implementação do TQM.

\section{Modelos de Implementação do TQM}

A pesar dos modelos definidos para a implementação do TQM, tais como os preconizados por SHIBA (1993) e MERLI (1993), é mister observar que cada empresa pode definir seu próprio modelo de implementação.

Ao contrário do que ocorreu na década de 80, quando várias empresas ocidentais tomaram a iniciativa de implementar o TQM baseando-se apenas em tentativa e erro, sem contar com um modelo consolidado, o que acabou provocando grande número de fracassos, atualmente as organizações já dispõem não só de modelos como também de exemplos de implementação bem sucedida, que podem servir como ponto de partida e orientação.

Esses modelos podem ser "adaptados" para cada empresa, levando em consideração os aspectos de sua própria cultura, tecnologia, características estruturais do negócio, maturidade da linha de produtos e estratégias competitivas.

É importante ressaltar que, mesmo em função da diversidade de formas de implementação, os princípios da nossa definição inicial sobre TQM permanecem em termos de: filosofia sistematizada, orientação para resultados, foco no cliente e no processo, envolvimento de todos $e$ liderança, conforme veremos adiante.

\subsection{Modelos de Implementação do TQM}

A seguir são apresentados os modelos de implementação do TQM preconizados por MERLI (1993), SHIBA (1993) e KAPLAN
(1995). Para cada modelo são mostradas as suas fases e respectivas linhas mestras. 
Tabela 1: Modelos Teóricos de Implementação do TQM

\begin{tabular}{|c|c|c|}
\hline \multirow[t]{2}{*}{ Modelo } & \multicolumn{2}{|c|}{ Características dos Modelos } \\
\hline & Fases & Linhas Mestras \\
\hline \multirow[t]{4}{*}{ Merli } & abordagem convencional & $\begin{array}{l}\text { qualidade do produto } \\
\text { ênfase em inspeção }\end{array}$ \\
\hline & $\begin{array}{l}\text { organização para o } \\
\text { aperfeiçoamento }\end{array}$ & $\begin{array}{l}\text { controle de processos } \\
\text { equipes de melhoria } \\
\text { ênfase em educação } \\
\text { equipes multifuncionais }\end{array}$ \\
\hline & gerência por processos & $\begin{array}{l}\text { ênfase na prevenção } \\
\text { políticas anuais } \\
\text { empowerment } \\
\text { desdobramento de políticas } \\
\text { gerência por processos } \\
\text { benchmarking }\end{array}$ \\
\hline & $\begin{array}{l}\text { implementação completa } \\
\text { do TQM }\end{array}$ & $\begin{array}{l}\text { policy deployment } \\
\text { daily-routine-work } \\
\text { análise de custos globais } \\
\text { gestão do tempo de ciclo } \\
\text { desdobramento da qualidade }\end{array}$ \\
\hline \multirow[t]{3}{*}{ Shiba } & orientação & $\begin{array}{l}\text { visão e missão da empresa } \\
\text { objetivos da qualidade } \\
\text { montagem da infra-estrutura da } \\
\text { qualidade }\end{array}$ \\
\hline & empowerment & $\begin{array}{l}\text { educação e capacitação } \\
\text { emprego de equipes } \\
\text { aplicação de ferramentas da } \\
\text { qualidade }\end{array}$ \\
\hline & alinhamento & $\begin{array}{l}\text { desdobramento de políticas e } \\
\text { objetivos } \\
\text { gerência por processos } \\
\text { gestão visual } \\
\text { daily-routine-work } \\
\end{array}$ \\
\hline \multirow[t]{4}{*}{ Kaplan } & conscientização & $\begin{array}{l}\text { reprodutibilidade dos processos } \\
\text { promoção do trabalho em equipe }\end{array}$ \\
\hline & embasamento & $\begin{array}{l}\text { educação e capacitação } \\
\text { inspeção em projeto e fabricação } \\
\text { prevenção de defeitos } \\
\text { redução de tempos de ciclos }\end{array}$ \\
\hline & gerência & $\begin{array}{l}\text { planejamento estratégico } \\
\text { trabalho em equipes } \\
\text { gerência dos processos } \\
\text { equipes multifuncionais } \\
\text { desdobramento da qualidade } \\
\end{array}$ \\
\hline & integração & $\begin{array}{l}\text { estratégia com foco no cliente } \\
\text { daily-routine-work } \\
\text { benchmarking }\end{array}$ \\
\hline
\end{tabular}




\subsection{Modelos Práticos de TQM}

A tabela 2 apresenta características dos de classe mundial.

modelos de TQM de empresas consideradas

Tabela 2: Modelos Práticos de Implementação do TQM

Fonte: Zairi (1994).

\begin{tabular}{|c|c|c|}
\hline Empresa & Políticas Orientadoras & Linhas Mestras do TQM \\
\hline Motorola & $\begin{array}{l}\text { aprendizagem contínua } \\
\text { inovação } \\
\text { desenvolvimento das capacita- } \\
\text { ções básicas } \\
\text { satisfação dos clientes } \\
\text { satisfação dos colaboradores } \\
\text { responsabilidade social }\end{array}$ & $\begin{array}{l}\text { policy deployment } \\
\text { programa six sigma de redução de } \\
\text { defeitos } \\
\text { redução do tempo de ciclo } \\
\text { gerência participativa } \\
\text { educação e treinamento } \\
\text { Motorola University } \\
\text { MBQNA }\end{array}$ \\
\hline IBM Rochester & $\begin{array}{l}\text { satisfação do cliente } \\
\text { satisfação dos colaboradores } \\
\text { melhoria contínua }\end{array}$ & $\begin{array}{l}\text { implementação em fases } \\
\text { empowerment } \\
\text { equipes multifuncionais } \\
\text { gerência do ciclo do tempo } \\
\text { benchmarking } \\
\text { parcerias com clientes } \\
\text { parcerias com fornecedores } \\
\text { gerência dos processos } \\
\text { MBQNA }\end{array}$ \\
\hline Xerox & $\begin{array}{l}\text { satisfação do cliente } \\
\text { satisfação dos colaboradores } \\
\text { retorno sobre os ativos } \\
\text { aumento do market-share }\end{array}$ & $\begin{array}{l}\text { policy deployment } \\
\text { benchmarking } \\
\text { equipes multi-funcionais } \\
\text { forte sistema de comunicação } \\
\text { empowerment } \\
\text { gestão por fatos e dados } \\
\text { gerência de processos } \\
\text { prêmios da qualidade }\end{array}$ \\
\hline Federal Express & $\begin{array}{l}\text { satisfação total do cliente } \\
\text { comprometimento com os } \\
\text { colaboradores } \\
\text { melhoria contínua }\end{array}$ & $\begin{array}{l}\text { empowerment } \\
\text { gerência por processos } \\
\text { times da qualidade } \\
\text { educação e treinamento } \\
\text { programas de reconhecimento } \\
\text { gerência por fatos } \\
\text { qualidade de vida dos colaboradores } \\
\text { MBQNA }\end{array}$ \\
\hline
\end{tabular}

Comparando-se os modelos preconizados por MERLI (1993), SHIBA (1993) e KAPLAN (1994) com as abordagens práticas empregadas por empresas de classe mundial, percebe-se que a essência, em termos de enfoque, segue os fundamentos do TQM.
Um aspecto importante a salientar, muito bem relatado por MAIN (1995), é que essas empresas adotaram a filosofia gerencial do TQM a partir de sofridas experiências, ou seja, estavam perdendo mercado para os competidores japoneses, com exceção da Federal Express, e tiveram como principal 
promotor da transformação o seu executivo principal e equipes da alta gerência.

Para essas empresas, que continuam a evoluir, o TQM foi a chave para a conquista de padrões de classe mundial de operação.

As empresas utilizam simultaneamente as abordagens de implementação tais como definidas por SMITH et al (1994), que as denominaram como planejamento, aprendizagem e visionária. São modelos baseados no entendimento das necessidades dos clientes, nos quais metas de melhoria são estabelecidas, monitoradas, desdobradas por toda a organização e vinculadas ao planejamento estratégico. Os processos são cons- tantemente alinhados às necessidades dos clientes, com desempenho superior, comparado ao dos competidores. Os modelos estão sedimentados em equipes multifuncionais e equipes da qualidade, constantemente treinadas, inclusive com a participação de fornecedores e, eventualmente, de clientes.

Observa-se, por fim, que, conforme já ressaltado por GARVIN (1991), o MBNQA não deixa de ser importante ferramenta para o planejamento e a implementação da qualidade pelas empresas, sendo um excelente padrão de referência para a consolidação da cultura da qualidade, como ocorre nas empresas mencionadas.

\section{Conclusões}

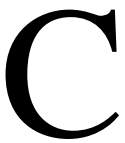

omo se pode verificar, existem vários caminhos para que uma empresa se torne uma organização de classe mundial, sejam eles baseados em modelos teóricos, com possíveis adaptações, ou pelo exemplo de empresas que já incorporaram o TQM ao seu modus vivendi.

Apesar dos conceitos que formam a filosofia do TQM serem até certo ponto produto de bom senso e relativamente simples de serem entendidos, a experiência tem demonstrado que sua implementação é extremamente difícil, em virtude da necessidade de uma profunda transformação cultural, principalmente por parte dos dirigentes das empresas. Seu comportamento (comprometimento, liderança e apoio ao processo do TQM) é a "molamestra” para o êxito da implementação dessa filosofia de gestão. (PORTER \& PARKER, 1993).

Outro aspecto a considerar na adoção dos princípios e filosofias preconizados pelo TQM, diz respeito aos fatores que contribuem para cercar de contingências específicas a sua implementação.

Apesar deste tema ser muito pouco explorado na literatura, fatores como o tipo da indústria, seu estágio de evolução (emergente, em crescimento, fragmentada, madura ou em declínio), a experiência da empresa na competição global suposição na cadeia de suprimento, para citar somente alguns, podem requerer abordagens e focos distintos na implementação do TQM.

Por fim, o que as empresas brasileiras, que experimentam intensa competição, tanto local como externa, podem aprender com estes modelos teóricos e práticos do TQM ? A nosso ver, algumas linhas de conduta devem ser apreciadas, quais sejam:

Independente do clima político e econômico do país, objetivos a longo prazo não devem ser deixados de lado, deve haver constância de propósitos;

Não se contentar somente com o certificado ISO 9000, apesar de sua importância competitiva para negócios atuais. O certificado está sendo considerado como elemento da qualidade compulsória, assim como serão os certificados na ISO 14000, que trata da qualidade ambiental e, futuramente, a ISO 18000, que trata da qualidade de vida e da segurança do empregado;

Entender com profundidade as bases, os princípios e filosofias que regem a competição global, ou seja, o TQM;

$\mathrm{O}$ bom senso sugere a adoção dos modelos de $2^{\text {a }}$ geração, os quais são orientados para resultados de melhoria no 
curto prazo principalmente quanto aos processos críticos;

O modelo de implementação deve ser próprio, e adaptado à cultura da empresa e sistematizado, considerando também as contingências específicas;

Criar o breakthrough necessário usando benchmarking intensamente e compartilhando experiência com outras empresas, do mesmo ramo ou não, no Brasil e em outros países;

Usar critérios de excelência empresarial como os preconizados pelo Prêmio Nacional da Qualidade, considerando também as contigências específicas; é importante ser o melhor naquilo que o cliente valoriza;

Rever as relações com os sindicatos, incorporando-os no esforço de TQM;

Não esperar pelo Estado para educar seus colaboradores internos; a empresa deve fazer esforço adicional;

Monitorar constantemente o impacto da evolução tecnológica sobre a economia e a sociedade e, por conseguinte, sobre as características estruturais do seu negócio; a disseminação de inovações e mudanças ocorre em cascata, geralmente dos países de industrialização avançada para os países de economia emergente, como é o nosso caso; a desatenção quanto a este aspecto pode fazer com que empresas maduras em relação ao TQM desapareçam; é preciso saber para onde, do ponto de vista do cliente, a qualidade está se movendo, bem como ter conhecimento da maneira pela qual os concorrentes estão atendendo.

Acreditamos que estar atento a essas questões pode ajudar consideravelmente as empresas na implementação de seu modelo de Gestão para a Qualidade Total.

\section{Referências Bibliográficas:}

AKAO, Y.: Practical Applications of Management by Policy. Japan Standards Association, Tokyo, 1988.

CAMP, R.: Benchmarking: the search for industry best practices that lead to superior performance. ASQC Quality Press, Milwaukee, 1989.

CONTI, T.: Self-Assesment and Strategic Improvement Planning. FPNQ, Seminário - Em Busca da Excelência, 1994.

CROSBY, P.B.: Qualidade é Investimento. José Olympio, Rio de Janeiro, 1984.

DEMING, W.E.: Out of Crisis, MA: MIT Center for Advanced Engineering Study, Boston, 1986.

DOBBINS, R.D.: “A Failure of Methods, Not Philosophy”. Quality Progress, vol 28, n 7, pp 31-33, July, 1995.

EARLY, J.F. \& GODFREY, A.B.: "But it Takes Too Long...” Quality Progress, vol 28, n 7, 5155, July, 1995.

FEIGENBAUM, A.V.: Total quality control, 3. ed. New York: Mc Graw-Hill, 1986.

Fundação para o Prêmio Nacional da Qualidade. Critérios de Excelência: o estado da arte da Gestão da Qualidade Total, São Paulo, 1995.
GALGANO, A.: Calidad Total: clave estratégica para la competitividad de la empresa. Ediciones Diaz de Santos, 1993.

GARVIN, D.: “Building a Learning Organization”. Harvard Business Review, pp. 78-91, JulyAugust, 1993.

GARVIN, D.A.: Gerenciando a Qualidade: a visão estratégica e competitiva. Qualitymark, Rio de Janeiro, 1992.

GARVIN, D.: "How the Baldrige Award Really Works". Harvard Business Review, pp. 80-95, November-December, 1991.

GITLOW, H.S. \& GITLOW, S.J.: Cómo Mejorar La Calidad y la Productividad con el Método Deming: una guía práctica para mejorar su posición competitiva. Editorial Norma S.A., 1989.

GOLD, B.: "Foundations of Strategic Planning for Productivity Improvement”. Interfaces, 15:3, pp. 15-30, May-June, 1985.

GREEN, C.: Os Caminhos da Qualidade: como vencer os desafios da economia global. Makron Books, 1995. 
HOOVER, H.W.: "What Went Wrong in U.S. Business's Attempt to Rescue Its Competitiveness?” Quality Progress, vol 28, n 7, pp 83-86, July, 1995.

IMAI, M.: Kaizen: a estratégia para o sucesso competitivo. 4. ed. Instituto IMAM, 1988.

ISHIKAWA, K.: Controle de Qualidade Total à maneira japonesa. Editora Campus, 1993.

JURAN, J.M.: Juran na Liderança Pela Qualidade. Pioneira, São Paulo, 1990.

KAPLAN, C. et al.: Secrets of Software Quality: 40 innovations from IBM, McGraw-Hill,1995.

KATZENBACH, J.R. \& SMITH, D.K.: "The discipline of Teams”, Harvard Business Review, pp. 111-120, March-April, 1993.

LARSON, P.D. \& SINHA, A.: “The TQM Impact: a study of quality managers perceptions”. Quality Management Journal, vol 2, $\mathrm{n}^{\mathrm{0}}$ 3, pp 53-66, Spring, 1995.

LES, L.: "Leading the Duck at Mission Control..." Quality Progress, vol 28, nº 7, 43-48, July, 1995.

MAIN, J.: Guerras Pela Qualidade: os sucessos e fracassos da revolução da qualidade - um relatório do Juran Institute. Editora Campus, 1995.

Malcolm Baldrige National Quality Award. 1995 Award Criteria, 1995.

MENDOLOWITZ, A.I.: Management Practices US Companies Improve Performance through Quality Efforts, United States General Account Office ( GAO/NSIAD-91-190), 1991.

MERLI, G.: Comekership: a nova estratégia para os suprimentos. Qualitymark Editora, 1994.

MERLI, G.: Eurochallenge: the TQM approach to capturing global markets. IFS Ltd, UK, 1993.

OSADA, T.: Housekeeping - 5 S's : cinco pontoschave para o ambiente da qualidade total. Instituto IMAM, 1992.
PORTER, L.J. \& PARKER, A.J.: 'Total quality management - the critical success factors”. Total Quality Management, vol 4, n 1, pp 13-22, 1993.

PRAHALAD, C.K. \& HAMEL, G.: "The Core Competence of the Corporation", Harvard Business Review, pp. 79-91, May-June, 1990.

SARAPH, J.V. et al.: "An instrument for measuring the critical factors of quality management”. Decision Sciences, vol 20, n ${ }^{0}$, pp. 810829, 1989.

SHIBA, S. et al:: A new American TQM: four practical revolution in management. Productivity Press, 1993.

SMITH et. al.: "Strategies for Managing the TQ Agenda”. International Journal of Operations \& Production Management. Vol. 14, $\mathrm{n}^{\circ} 1$, pp. 7588, 1994.

TAMINI, N. et al.: "Assessing the Psychometric Properties of Deming's 14 Principles”. Quality Management Journal, vol 2, $\mathrm{n}^{\circ}$ 3, pp 38-52, Spring, 1995.

TAGUCHI, G.: Introduction to Quality Evaluation and Quality Control. Japanese Standards Association, Tokyo, 1978.

TRIBUS, M.: Anotações de classe no curso Planejamento e Gestão da Qualidade, $1^{\circ}$ período 195, Departamento de Engenharia de Produção, POLI/USP.

WOMACK, J.P. \& JONES, D.T.: "From Lean Production to the Lean Enterprise". Harvard Business Review, pp. 93-103, March-April, 1994.

ZAIRI, M.: Measuring Performance for Business Results. Chapman \& Hall,1994.

\section{THE MEANING OF TQM AND PHASE-IN STRATEGIES}

\section{Abstract}

Begining with a sound analysis of Deming's 14 principles, the article explores the meaning of TQM according to its main fundamental elements: customer focus, process focus, employee commitment, leadership, results orientation and learning. The relationship among these elements is shown, as well as the management approaches to implement this new business philosophy. The theoretical TQM models are also presented, with the practical approaches used by world class companies. The TQM implementation critical success factors are adressed and several suggestions are given to Brazilian companies which aim to become competitive enterprises. 
Key-words: quality, total quality, quality management, phase-in models, global competition. 